\title{
Educação em Astronomia: investigando aspectos de conscientização socioambiental sobre a poluição luminosa na perspectiva da abordagem temática
}

\author{
Astronomy education: investigating aspects of social \\ and environmental awareness of light pollution \\ with a thematic approach
}

\author{
Fabiana Andrade de Oliveira ${ }^{1}$. Rodolfo Langhi ${ }^{1}$
}

\begin{abstract}
Resumo: Esta pesquisa consiste na elaboração de uma sequência didática temática, cujo tema foi a Poluição Luminosa, aplicada em uma turma de Ensino Médio, objetivando investigar os aspectos de tomada de consciência socioambiental que podem ser promovidos acerca deste tema. Seguindo alguns pressupostos da perspectiva da Abordagem Temática Freiriana, que propõe a escolha de um tema que represente um problema para os sujeitos, iniciou-se esta sequência a partir da falta de iluminação pública próxima à escola participante da investigação. Para as análises, utilizamos as atividades desenvolvidas pelos alunos e as observações dos diários do pesquisador. Mediante a metodologia da Análise Textual Discursiva, os resultados revelam que: os alunos desconhecem a poluição luminosa e seus efeitos sob o céu noturno; não possuem uma postura inicial de preocupação com questões ligadas ao meio ambiente; apresentaram, progressivamente, noções acerca da poluição luminosa, apesar de certa resistência com relação às práticas dialógicas do professor.
\end{abstract}

Palavras-chave: Ensino de Astronomia. Conscientização socioambiental. Poluição luminosa. Análise textual discursiva. Ensino Médio.

\begin{abstract}
This paper presents the development of a thematic sequence, whose theme was Light Pollution. It was applied in a group of students at high school to investigate aspects of social and environmental awareness that could be promoted based on this theme. We followed some assumptions from the perspective of a Freirean Thematic Approach, in which the Theme must represent a problem for students. This sequence was structured from a specific local problem: the lack of street lighting in the region around the school of these students. The activities developed by the students during the classes and the observations by the researcher diary were analyzed through Discourse and Textual Analysis. We obtained as results: the students are unaware of light pollution and its effects under the night sky; they aren't concerned about issues relating to the environment; they construct progressive notions about the light pollution; we noticed some resistance from students against this dialogical teacher practice.
\end{abstract}

Keywords: Astronomy education. Social and environmental awareness. Light pollution. Discoursive textual analysis. High School.

\footnotetext{
${ }^{1}$ Centro de Ciências Exatas e Tecnologia, Universidade Federal de Mato Grosso do Sul (UFMS), Campus Universitário, CEP 79070-900, Campo Grande, MS, Brasil. E-mail: anafabi.ufms@gmail.com
} 


\section{Introdução}

Pesquisas demonstram a importância da inserção da Astronomia no ensino formal, sugerindo que esta possui caráter motivacional; trata de fenômenos cotidianos; está presente nos veículos de comunicações em que são constantemente discutidas as descobertas astronômicas; além de proporcionar discussões históricas e filosóficas sobre a evolução desta como ciência (GAMA; HENRIQUE, 2010; KANTOR, 2001; LANGHI, 2011).

Sugestões quanto à forma de trabalhar a Astronomia no ensino encontram-se nos Parâmetros Curriculares Nacionais (BRASIL, 2002). Segundo estes documentos, esta deve ser abordada de forma integrada às disciplinas tradicionais. Neste sentido, Kantor (2001) aponta que esta ciência não pode ser apenas somada ao currículo, contribuindo, ainda mais, para a fragmentação do conhecimento. Segundo o autor, uma abordagem aplicável seria a articulação da Astronomia com as disciplinas regulares do currículo.

Conforme Gama e Henrique (2010), a Astronomia, quando apenas acrescentada às disciplinas de forma superficial, não potencializa uma problematização adequada e nem permite uma abordagem por meio de temáticas motivadoras. Nesta direção, os resultados de pesquisas no Ensino de Física apontam, como possibilidade, a reconfiguração do currículo escolar com base em temas, destacando que tal modalidade de ensino permite: a contextualização e a interdisciplinaridade (DELIZOICOV; ANGOTTI; PERNAMBUCO, 2002), discussões problematizadoras com olhar crítico sobre a epistemologia e a natureza da Ciência (ALBUQUERQUE; LEITE, 2010; GAMA; ZANETIC, 2009), inserir problemáticas pertencentes à realidade do indivíduo (DELIZOICOV, 1983), e abordar questões com enfoque na Ciência, Tecnologia e Sociedade (SANTOS; MORTIMER, 2002).

Buscando referenciais na reformulação curricular para um ensino comprometido com a formação cidadã (CARVALHO; GIL-PÉREZ, 1998; DELIZOICOV, 1983; REZENDE; OSTERMANN; FERRAZ, 2009; VILLANI, 1984;), desenvolvemos, nesta pesquisa, uma proposta temática que contemplou a Astronomia de forma que esta estivesse articulada à Física, buscando-se romper com a fragmentação do conhecimento, a qual distancia o conhecimento científico da realidade vivenciada pelos sujeitos, e não possibilita a formação consciente e reflexiva dos mesmos. Estruturou-se uma sequência didática com base na metodologia dos Três Momentos Pedagógicos (DELIZOICOV; ANGOT'TI; PERNAMBUCO, 2002), articulando a Astronomia e a Física para compreender o tema Poluição Luminosa (PL), a partir de um viés científico, e objetivando-se discutir esta temática reflexivamente, ao considerar o céu como patrimônio da humanidade, apontando a perda do direito de todos em observar o céu noturno sem poluição.

Esta sequência didática, aplicada nas aulas regulares de Física em uma turma de segundo ano do Ensino Médio, permitiu-nos atingir o objetivo geral deste estudo, a saber, investigar, nos discursos e ações dos sujeitos, elementos que apontem o elenco de aspectos de conscientização socioambiental sobre a problemática da PL. É importante salientar, porém, que a escolha deste tema antecedeu todo o processo, pois se deu por meio de discussões coletivas com alguns dos atores envolvidos, obtendo-se, como ponto de partida para discussão escolar, um problema local vivenciado pelos sujeitos: a falta de iluminação pública na região em que se encontra a escola.

Durante a etapa de aplicação da proposta, levantaram-se, inicialmente, as concepções que os grupos de alunos possuíam sobre a iluminação próxima à escola e os aspectos que considerariam pertinentes para uma iluminação adequada. Analisamos a gradual construção de 
uma atitude crítica dos alunos com relação a este problema social local, atingindo-se um posicionamento propenso a mudanças. Os registros das observações da pesquisadora e as atividades desenvolvidas pelos alunos constituíram-se em fonte de dados para análise desta investigação, a qual, metodologicamente, está fundamentada nos procedimentos da Análise Textual Discursiva (MORAES, 2003). Isto nos possibilitou constatar não apenas as tomadas de consciência destes sujeitos acerca da PL, mas, também, construir um elenco de aspectos gerais desta conscientização socioambiental, os quais poderão servir de embasamento para futuras investigações nesta linha, além de proporcionar subsídios para se repensarem modelos de formação de professores.

Diante do exposto, levantamos o seguinte questionamento central desta pesquisa: quais aspectos assumem os elementos de conscientização socioambiental sobre a PL a partir de uma proposta de ensino pautada na abordagem temática aplicada em um grupo de alunos do Ensino Médio? Ressaltamos que este estudo realizou-se em duas etapas, sendo a primeira a estruturação inicial da sequência didática (OLIVEIRA; LANGHI, 2011), e a segunda, a análise da aplicação da mesma, obtendo-se os resultados finais aqui apresentados.

\section{Referenciais adotados}

A elaboração de um programa de ensino, em que os temas assumem o papel de objetos de estudos, é umas das premissas da abordagem temática: "entende-se a abordagem temática como perspectiva curricular cuja lógica de organização é estruturada com base em temas, com os quais são selecionados os conteúdos de ensino das disciplinas" (DELIZOICOV; ANGOTTI; PERNAMBUCO, 2002, p. 189).

Essa dinâmica de estruturação do currículo permite a contextualização do ensino de acordo com as intenções de seu idealizador. Conforme Gehlen (2009), embora a abordagem temática proposta por Delizoicov, Angotti e Pernambuco (2002) destaque a perspectiva freiriana, é possível explorar demais referenciais nesta perspectiva de ensino, como o enfoque CTS (Ciência Tecnologia e Sociedade), proposto por Santos e Mortimer (2002) e os Temas Transversais propostos pelos Parâmetros Curriculares Nacionais ( $\mathrm{PCN}$ ), além de outros identificados por Gehlen, Maldaner e Delizoicov (2012).

Por isso, alguns pressupostos freirianos foram adotados na presente pesquisa, dada a sua pertinência com os objetivos propostos. De fato, Freire (1984) atribui um papel especial à educação, que é a formação de indivíduos conscientes de suas contradições sociais. Para isso, sua perspectiva abrange práticas educativas que permitam a imersão destes indivíduos em seu contexto social e, por meio de uma postura crítica, atuem de forma a promover a transformação. Com isso, a perspectiva educacional proposta por Freire parte do caráter transformador que os sujeitos possuem sobre a sua realidade, visando sua construção crítica, em uma dinâmica de ensino fundamentada na práxis, ou seja, "na ação e reflexão dos homens sobre o mundo para transformá-lo" (FREIRE, 1984, p. 40).

Assim, a concepção de conscientização adotada nesta pesquisa é aquela apresentada por Freitas (2004), que não se limita à tomada de consciência, mas se complementa a partir da ação transformadora. Neste sentido, a atuação do professor, enquanto um agente de ação e de transformação, torna-se fundamental neste processo, pois seu papel "intelectual crítico" (GIROUX, 1997) na autonomia docente que lhe cabe (CONTRERAS, 2002) embasa-se em 
uma formação (inicial e continuada) reflexiva, e não, simplesmente, conteudista e tecnicista, ou seja, sob a racionalidade técnica (SCHÖN, 1983; ZEICHNER, 1993).

No entanto uma prática ainda dominante no ensino é aquela que valoriza apenas a transmissão de conhecimento em uma dinâmica narrativa dos conteúdos, tendo-se como resultado a transmissão acrítica e apolítica do conhecimento, em que sua origem e processo de construção são negligenciados. Freire (1984, p. 65) sinaliza que a "narração de conteúdos [...], tende a petrificar-se ou fazer-se algo quase morto, sejam valores ou dimensões concretas de sua realidade". Assim, denomina-se educação bancária o ensino cuja prática é a de dissertação do conhecimento, ou seja, "o educador faz comunicados e depósitos, e os educandos meras incidências, recebem pacientemente, memorizam e repetem” (FREIRE, 1984, p. 66). Para este autor, "quanto mais se exercitem os educandos no arquivamento dos depósitos que lhe são feitos, tanto menos desenvolverão em si a consciência crítica de que resultaria a sua inserção no mundo, como transformadores deles" (FREIRE, 1984, p. 68).

Espera-se, então, que um ensino sob a perspectiva temática parta de uma situação vivenciada pelos sujeitos, de seus problemas, sendo assim compreendida como uma dinâmica problematizadora. No contexto do ensino problematizador, um importante papel é atribuído ao diálogo, como o mediador entre o mundo e os sujeitos. Segundo Freire, o educador (professor), ao idealizar um programa de ensino baseado na perspectiva problematizadora e dialógica, não deve embasar-se em sua visão pessoal de realidade, mas "partir da situação presente, existencial, concreta, refletindo o conjunto de aspirações do povo" (FREIRE, 1984, p. 101). Deste modo, entende-se a importância de o ponto de partida do ensino ser a realidade dos indivíduos, uma vez que, a função da abordagem temática freiriana é muito mais que organizar o currículo escolar, pois também traz à tona um problema de dimensão histórico-cultural, o qual necessita ser compreendido e superado criticamente Gehlen (2009). Assim, entende-se que esta perspectiva possui objetivos maiores que somente a conceituação científica, pois sua abordagem é Temática. É por meio do conhecimento historicamente construído do professor e as contradições dos alunos que ambos caminharão rumo à compreensão do Tema.

\section{Critérios de escolha do tema}

Tomando-se como base as premissas da perspectiva freiriana, conforme brevemente acima exposto, esta pesquisa envolveu discussões preliminares com alguns atores da escola colaboradora, abordando questões sociais locais, buscando, assim, por problemáticas que permitissem as manifestações sociais dos sujeitos participantes desta intervenção, sendo algumas destas relacionadas à poluição luminosa (PL). Dessa forma, salientamos que esta proposta visa potencializar a compreensão da PL sob o viés do conhecimento científico, promovendo a discussão dos efeitos desta sob o céu noturno e a tomada de consciência voltada a transformações sociais locais. Por isso, esta pesquisa focou seu desenvolvimento em uma contradição social vivenciada com o tema em questão, a PL, o qual possui relações diretas com a Astronomia.

No entanto, é importante salientar que este trabalho não contemplou o completo processo da Investigação Temática proposta por Freire e apresentada, sistematicamente, em cinco etapas por Delizoicov (1983), e Delizoicov, Angotti e Pernambuco (2002). Nossa proposta enquadra-se na identificação de um problema social local sem as etapas dos diálogos descodifi- 
cadores e do trabalho de uma equipe interdisciplinar para elaborar um programa. Neste sentido, de acordo com Gehlen, Maldaner e Delizoicov (2012), ao definirmos a situação problemática para este trabalho, utilizamos uma necessidade do contexto social no qual o estudante está inserido, sem, contudo, caracterizar-se como uma perspectiva freiriana em sua completude, mas uma adaptação da investigação temática. Assim, após discussões iniciais entre o professor de Física da escola participante deste trabalho e os pesquisadores, constatou-se que uma das problemáticas sociais locais, a falta de iluminação nas ruas próximas à escola, promoveria discussões que seriam pertinentes ao contexto da PL.

Atualmente, devido ao contexto tecnológico no qual está inserida a sociedade moderna, mostra-se complicada uma vida sem iluminação artificial. No entanto, o inadequado planejamento desta acarreta a PL, a qual é causada pelo excesso, ou, mesmo, pelo direcionamento incorreto da iluminação artificial. Pesquisas apontam as suas consequências no meio ambiente, na qualidade de vida dos seres vivos, na economia e, especialmente, no céu noturno (BARGHINI, 2010; GARGAGLIONI, 2007).

Conforme Langhi (2009), um dos efeitos desta poluição recai, também, sobre o aspecto financeiro, pois o desperdício de energia em um poste fica em torno de $30 \%$ a $40 \%$, ou seja, essa energia é usada iluminando lugares desnecessários, a exemplo do céu noturno. Por este motivo, ambientalistas sinalizam a importância da economia energética, sobretudo pelo fato de que $19 \%$ da energia elétrica produzida são utilizados na iluminação do planeta, somando-se a isso, o fato de que a maior parte das matrizes energéticas são usinas termoelétricas a carvão, altamente poluentes.

Em um documento para o Ano Internacional da Astronomia, em Portugal, Almeida (2009) revela a falta de tomada de consciência neste sentido, quando apresenta a difundida concepção da população de que a grande luminosidade artificial é inevitável e que serve como um indicador de progresso e modernidade de uma nação. Por isso, a PL tem sido tema constante em debates na comunidade astronômica, a exemplo da XXVII Assembleia Geral da União Astronômica Internacional (IAU), realizada em 2009, no Rio de Janeiro; no XIV Encontro Nacional de Astronomia (ENAST), realizado em 2011, na cidade de São Paulo, e no VIII Encontro Paranaense de Astronomia (EPAST), realizado em 2011 no Polo Astronômico Casimiro Montenegro Filho, nas dependências da usina hidrelétrica de Itaipu, destacada entidade abastecedora de energia elétrica do País e, portanto, fonte para a iluminação pública.

Flório (2009) aponta diversos projetos organizados pela Unesco (Organização das Nações Unidas para a Educação, a Ciência e a Cultura) e IAU, que visam a proteção do céu noturno, dentre eles o Dark Skies Awareness. De acordo com a autora, o artigo 23 da Constituição Federal do Brasil estabelece, como competência comum da União, dos estados, do Distrito Federal e dos municípios, proteger o meio ambiente e combater a poluição em qualquer de suas formas.

Porém, acreditamos que a tomada de consciência acerca destes direitos, quando trabalhada na escola, ainda durante a formação do cidadão, conforme apontam os PCN (BRASIL, 1999), favorece a incorporação de questões ambientais ao currículo escolar. Estes documentos consideram tais questões como parte integrante do exercício da cidadania, e atribuem um importante papel do ensino como fomentador de sujeitos comprometidos com o meio ambiente, ou seja, como atores sociais posicionando-se de forma reflexiva diante de questões ambientais, e, diante de atitudes transformadoras, contribuam com os interesses da sociedade em geral. 


\section{Estruturando a proposta didática}

A estruturação das aulas seguiu a metodologia dos Três Momentos Pedagógicos (DELIZOICOV; ANGOTTI; PERNANBUCO, 2002). Segundo Gehlen (2009), os momentos pedagógicos apresentam um papel organizacional no planejamento dos conteúdos a serem desenvolvidos em sala de aula, constituindo uma dinâmica de três etapas: problematização (apresenta-se um desafio a fim de expor sobre o que os alunos estão pensando sobre as situações reais), organização do conhecimento (sob mediação do professor, estudam-se, sistematicamente, os conhecimentos selecionados como necessários para a compreensão do tema e da problematização inicial) e aplicação do conhecimento (aborda-se, sistematicamente, o conteúdo que já vem sendo incorporado pelo aluno, para analisar situações e interpretar tanto as situações iniciais que determinaram seu estudo como outras situações diferentes que podem ser compreendidas pelo mesmo conhecimento).

Apresentamos, a seguir, uma visão geral da sequência didática. A mesma apoiou-se nos referenciais adotados e discutidos anteriormente, sendo apresentada com maiores detalhes em Oliveira e Langhi (2011).

Problematização (duas aulas): Apresentação de uma reportagem local em que mostra o problema de falta de iluminação na região próxima à escola. Em seguida, fotos foram apresentadas aos alunos, algumas com luminárias dispersando a luz, outras de lugares iluminados adequadamente (sem avisar do que se tratam em cada caso), promoveu a discussão coletiva sobre os aspectos que os alunos considerariam necessários para iluminar os bairros em que moram. A partir do diálogo em sala, os alunos responderam às perguntas problematizadoras: $\mathrm{Na}$ sua opinião, quais os problemas gerados pela falta de iluminação pública? Quais são os aspectos essenciais para que haja uma iluminação eficiente nos bairros? Por fim, houve uma aula dialógica sobre o tema poluição, seus tipos e suas implicações.

Organização do conbecimento (cinco aulas): Envolveu uma atividade de observação do céu noturno, cujo objetivo foi apresentar, informalmente, a PL, a partir da identificação da constelação de Escorpião no céu noturno e utilizando cartões da PL elaborados para a realização da "Maratona da Via Láctea", uma das atividades promovidas no Ano Internacional da Astronomia (MARATONA..., 2009). Esta atividade dialógica possibilitou que os grupos de alunos comparassem o céu dos cartões com o céu local, atribuindo uma nota ao céu, conforme indicado no cartão (esta nota refere-se à magnitude aparente limite, cujo número aumenta à medida que se torna possível observar estrelas menos brilhantes; deste modo, um céu de nota 7 corresponde a um céu sem poluição luminosa). Embora não trabalhadas, naquele momento, as definições formais de PL e de magnitude aparente, os alunos foram conduzidos a justificar suas observações e notas atribuídas ao céu. Na segunda atividade, a PL foi abordada por meio de um texto com figuras e fotos, descrevendo os seus efeitos no meio ambiente e no céu, usando alguns conceitos de óptica, tais como: raios de luz, fontes de luz, fontes secundárias, propagação retilínea da luz. O estudo destes conceitos ocorreu dialogicamente a partir da necessidade de se entender a PL utilizando os conceitos científicos. Numa abordagem prática, utilizou-se um simulador de eclipses do Sol e da Lua (ROS, 2006), visando discutir o conceito de sombra e penumbra, a propagação da luz e o fenômeno dos eclipses. Foram também apresentadas figuras com os aspectos necessários para a boa iluminação, como, por exemplo: o tipo de lâmpadas, posicionamento dos postes etc. 
Aplicação do conbecimento (duas aulas): Um questionário foi aplicado aos alunos, a fim de retornar a problematização inicial e avaliar, individualmente, a construção da conscientização procurada neste estudo. Solicitou-se uma produção dos alunos de uma proposta de solução para um protótipo de poste, em que deveriam projetar um aparato que reduzisse a PL. Para isso, foi necessário que eles se apoiassem nos conceitos científicos abordados em sala e nas imagens exibidas durante as aulas desta sequência didática. Quando terminaram de apresentar as soluções, exibiram-se as imagens de um projeto realizado por Diniz (1999), cuja iluminação de um condomínio foi corretamente modificada para a redução da PL.

Deste modo, a aplicação desta sequência didática, com o tema "Da falta de iluminação pública à poluição luminosa: problemáticas que se complementam na região de...", prestou-se como fonte de dados para esta pesquisa.

\section{Encaminhamentos metodológicos da pesquisa}

Para este estudo, utilizamos, como uma das fontes de dados, os materiais produzidos pelos alunos. Estes consistiram de um questionário sobre o texto (aula 4), as questões problematizadoras (aula 1) e uma avaliação escrita (aula 8).

Além desta fonte de dados, a pesquisa envolveu o uso de diários de pesquisa (FLICK, 2009). Nestes, são registrados, pelo pesquisador, dados referentes à observação de campo, as experiências, dificuldades, entrevistas e fatos. Assim, a produção escrita dos alunos e o registro de suas ações no diário do pesquisador complementaram-se para formar o corpo de dados para esta investigação.

Esta ação envolveu uma turma noturna do segundo ano do Ensino Médio de uma escola pública da cidade onde a universidade dos pesquisadores está localizada. Foram 15 alunos participantes, sendo oito do sexo feminino e sete do masculino. Ressalta-se que o professor desta turma já estava envolvido com os aspectos metodológicos dos momentos pedagógicos e que a pesquisadora atuou como observador destas aulas, registrando os fatos relevantes aos propósitos desta investigação por meio do diário de pesquisa (FLICK, 2009).

Adotamos como referencial metodológico, para a análise destes dados, a Análise Textual Discursiva (MORAES, 2003). Este procedimento de análise consiste em um intenso processo de interação com a informação, objetivando a compreensão por meio de um processo de construção de novos entendimentos a partir de uma sequência recursiva de três componentes: desconstrução dos textos (a unitarização), estabelecimento de relações entre os elementos unitários (a categorização), e o captar do novo emergente, em que a nova compreensão é comunicada e validada (MORAES, 2003). As categorias podem ser estabelecidas a priori, baseadas nos objetivos da investigação e na fundamentação da pesquisa. Além disso, pode ocorrer, no momento de interação do pesquisador com o corpus do texto, a constatação de relações entre as unidades de significados, antes não previstas, resultando, assim, no surgimento de novas categorias, as quais devem ser definidas como emergentes. Este novo emergente é apresentado no final deste texto como resultado principal da pesquisa. 


\section{Análise dos dados constituídos}

Levando em conta os procedimentos metodológicos da Análise Textual Discursiva, os objetivos desta pesquisa e a fundamentação teórica sob a perspectiva da abordagem temática, efetuamos a análise dos discursos e das ações dos grupos de alunos, registrados em suas atividades de sala de aula (AT) e no diário do pesquisador (DP). As análises se deram conforme as seguintes categorias a priori: consciência primeira, manifestações de aspectos da PL e tomada de consciência. Entretanto, durante o processo de análise de pesquisa, fez-se necessária a emersão de nova categoria, resistência à proposta (pois o referencial metodológico adotado assim o permite), referente à postura dos alunos com relação a esta "nova" dinâmica de sala de aula.

Apresentamos, a seguir, alguns recortes representativos das suas respectivas unidades de significado. As transcrições em itálico preservaram a ideia original dos discursos dos agentes da pesquisa, mas seus erros de redação foram corrigidos, já que não é importante para este estudo manter a forma original das falas. Cada trecho discursivo é seguido de interpretações da parte dos pesquisadores segundo os referenciais metodológicos adotados, comunicadas como o conjunto de aspectos voltados à construção de uma consciência socioambiental sobre a PL, segundo o aporte teórico anteriormente discutido (em vista das limitações de espaço deste texto, apresentamos apenas alguns recortes, mas as transcrições completas, inclusive os erros de redação conservados, poderão ser encontradas em Oliveira, 2011).

Consciência primeira: nas discussões iniciais com o grupo de alunos, questionouse acerca de quais eram os problemas de infraestrutura em seus bairros. Estes, por sua vez, apontaram a falta de iluminação como a geradora de outro problema: a falta de segurança. Observou-se que os questionamentos se deram em quatro aspectos:

a) Indicaram que a solução seria apenas colocar postes com lâmpadas nas ruas. No entanto, não foi explicitada nenhuma preocupação de que forma promovê-la. Alguns deram ênfase quanto ao aumento da quantidade de postes em um local, evidenciando que desconhecem algum tipo de problema com relação à iluminação exagerada.

AT: Tem que ter iluminação, não só de um lado da calçada e sim dos dois lados; na rua também, para evitar acidente, assaltos e para melhorar a segurança da população. DP: Durante as apresentações, os alunos discordaram muito entre si a respeito do lugar mais adequadamente iluminado. Para eles, não pode ter uma região no espaço "sem luz". Na visão deles, o certo seria iluminar o máximo possível [...]. Alguns alunos afirmaram que o correto seria iluminar os dois lados da rua.

b) Apontaram alguns dos problemas sociais ocasionados pela falta de iluminação. Estas situações problemáticas, segundo Freire (1984), representam as manifestações das contradições sociais. Notou-se a emersão, nas discussões, dos problemas locais, como a segurança pública e a facilidade quanto ao uso de drogas. Nesta etapa inicial, os indivíduos não pareceram se atentar a questões ambientais, demonstrando a necessidade da construção de um indivíduo atento não somente a problemáticas sociais locais, mas, também, com questionamentos de maior amplitude, tais como a defesa ambiental global. 


\begin{abstract}
AT: Precisa de iluminação perto das casas abandonadas. Segurança para não ter muitos roubos. Mais policiamento para acabar com as drogas.
\end{abstract}

c) Demonstraram que desconheciam a PL; mesmo o professor questionando se o céu noturno corresponde ao de magnitude limite 7 do cartão em uso (MARATONA..., 2009), os grupos justificaram que isso ocorre devido à distância entre a Terra e as estrelas. Explicam o céu como uma esfera incrustada de estrelas que se encontram à mesma distância em relação a eles, ou seja, não possuíam a noção de magnitude aparente ou diferenças de distâncias dos corpos celestes.

AT: Mas eu acho que se estivéssemos mais alto, como num avião ou em um ponto mais alto, daria para ver mais estrelas.

AT: Eu escolbi magnitude 5. Na minha opinião ela é a que melhorpodemos enxergar e comparar com a constelação de Escorpião. Eu acho que as outras magnitudes não permitem comparar. Talvezporque as nuvens estejam cobrindo as estrelas, ou porque estamos longe. Acho que depende do lugar de onde observamos o céu.

d) Estabeleceram relações entre elementos poluidores e a visualização do céu, mas os identificaram como poluição visual e do ar.

DP: Percebeu-se que a poluição visual foi associada à poluição luminosa [...]. Os alunos responderam que a poluição do ar estava relacionada à aula de observação do céu; segundo eles, a aula anterior serviu como um exemplo de poluição do ar e a visual, mostrando uma associação da PL com a poluição visual.

Manifestações de aspectos sobre a PL: nesta categoria, os grupos apresentaram respostas que continham os aspectos pertinentes para compreensão da PL, após a superação das etapas iniciais da sequência didática aplicada à turma. Assim, identificou-se esta categoria como uma aproximação ao contexto da PL de forma indireta, abrangendo os seguintes aspectos:

a) Identificaram certas irregularidades na iluminação pública, mas não souberam explicá-las. Um dos grupos demonstrou determinados aspectos pertinentes à PL, tais como: sua origem, consequências, e sua relação com a poluição. Para esses indivíduos, esta proposta permitiu que eles reconhecessem a PL em termos científicos, embora conhecessem, de modo geral, as características substanciais que levam à PL.

DP: No final, o professor questionou uma aluna a respeito do céu da fazenda em comparação ao céu da cidade. Ela explicou a diferença entre ambos como consequência da iluminação. Outro aluno complementou sua explicação afirmando que a luz é espalhada na atmosfera. No entanto, em um primeiro momento, eles não conseguiam relacionar esta explicação ao que ocorre nas fazendas e ao que estavam observando ali na quadra da escola, usando os cartões [...]. Quando o professor mostrou imagens (usando um projetor) como exemplos de locais sendo iluminados à noite, um aluno questionou o fato de não ter estrelas no céu das fotos. 
b) Durante o segundo momento pedagógico, chegaram a fazer referências aos conceitos da Física, ao indicarem a direção dos feixes de luz no espaço quanto ao local que se pretende iluminar.

AT: Lâmpadas de maior potência, lâmpadas iluminando para os lados e para cima e não iluminando lugares desnecessários [...]. Se cada projetor refletir para baixo a luz que iria para cima e para os lados, melhora-se a iluminação na área que interessa iluminar.

AT: Porque existem pontos de iluminação para cima e para os lados em vez de iluminar somente as áreas pretendidas. Isto resulta numa inadequada iluminação e aí que vem o desperdiço [...]. Em uma iluminação adequada, pode-se observar todo o ambiente sem luz excessiva ou iluminação inúteis.

AT: A luz é desperdiçada quando ela ilumina os pontos não necessários, por exemplo, iluminar a copa das árvores [...]. A iluminação adequada seria aquela que ilumina os pontos importantes como uma rodovia, ao fixar a luz, somente na estrada, ajudando na visualização dos condutores.

Tomada de consciência: neste momento, buscou-se investigar, a partir dos pressupostos freirianos, a superação das situações-limite por parte dos sujeitos. A análise das avaliações escritas aplicadas nesta turma posicionou os seguintes aspectos:

a) Quando questionados novamente acerca dos aspectos essenciais considerados como uma "boa iluminação" (PL reduzida), demonstraram que existe a preocupação quanto à forma de iluminação, buscando evitar o desperdício. Novamente, surgiu a questão do desperdício de energia como uma preocupação para estes indivíduos, porém, seus argumentos incluíram, nesta fase, conceitos de óptica e astronomia, bem como os aspectos abordados em sala nas discussões sobre a forma de iluminar e o desperdício de energia.

AT: Que se coloquem luminárias corretas nos postes evitando o desperdício de energia. AT: A iluminação deve estar para baixo e não para cima ou para os lados, pois isso seria desperdício de luz:

AT: Planejamento das lâmpadas adequadas para os postes.

DP: Questionaram a falta de planejamento quanto à iluminação pública. Declaração notável de um aluno: 'Nossa! Esse poste desperdiça muito, olha a luzindo para os lados!’’...] Quando uma aluna disse não haver iluminação necessária, a outra colega a corrigiu dizendo: [necessária tem]; o que não tem é iluminação adequada! E enfatizou a palavra "adequada".

b) Quando questionados se a PLé sinal de progresso, apresentaram, em suas respostas, um mergulho crítico no contexto social no qual estão inseridos, demonstrando que buscaram compreender o significado de progresso neste contexto, a partir de uma posição contestadora. Atinge-se, assim, o objetivo principal desta proposta e, também, umas das sugestões dos PCN (BRASIL, 1999), a saber, a formação de um indivíduo crítico perante as problemáticas sociais.

AT: Não, pois a iluminação deve ser correta e eficaz; para satisfažer a população é preciso ocorrer o progresso e não o desperdício. 
AT: O progresso não quer dizer que pode haver desperdício de recursos, afinal o progresso é o resultado da tentativa de melhorar o que já temos.

AT: Com luzes inadequadas instaladas incorretamente se gasta mais energia; desperdício não é sinônimo de progresso.

c) Quando questionados sobre a forma de a PL prejudicar o céu noturno, demonstraram seu reconhecimento.

AT: A poluição luminosa, devido à maneira de iluminação errada no poste, faz. o céu ficar muito claro e faz com que não possamos enxergar as estrelas. Por isso, em fazendas ou cidades com pouca iluminação, a visão das estrelas no céu é melhor.

AT: Ela ilumina muito o céu, ofuscando o brilho das estrelas.

d) No terceiro momento pedagógico, evidenciaram a construção de competências e habilidades para a elaboração de um protótipo de poste de iluminação pública respeitando-se as considerações sobre a PL e o conhecimento científico trabalhado durante o segundo momento pedagógico. Os resultados indicam um modelo formativo sob um perfil crítico (LANGHI; NARDI, 2011), levando seus alunos a uma condição "ativista" no sentido de movê-los à ação transformadora local, segundo a visão freiriana de educar para transformar (FREITAS, 2004).

DP: Os alunos apontaram que a estrutura que envolvia a lâmpada do poste era um pouco transparente. Que não tinha que ficar angulado, mas reto, que a lâmpada era forte, tinha que usar uma menos brilhante [...]. Um dos alunos pegou uma folha branca e cobriu os lados do poste miniatura. Mesmo não mudando muita coisa, ele disse que tinha de fazer isso. Usando um cartão preto, ele repetiu a ação, mostrando melhorias no protótipo. Alguns alunos falaram que o papel e a estrutura que envolvia a lâmpada do poste tinham de ser escuros (opacos) e que devido a esta modificação do poste, uma lâmpada menos potente poderia substituir a existente sem perda na eficiência da iluminação.

Resistência à proposta (a categoria emergente): houve fortes indicativos de resistência à metodologia diferenciada do professor, sob a perspectiva da abordagem temática em aulas dialogadas.

a) A postura dialógica do professor incomodou a maioria dos alunos, demonstrando que estavam habituados com um ensino "depositário", permeado de respostas prontas, em que o único esforço é o de armazenar informação, e não com a dinâmica de reflexão e investigação dos fenômenos, conforme fundamentada no aporte teórico desta pesquisa. De fato, a formação inicial do professor, na maioria dos casos, parece ainda se enquadrar no modelo formativo conteudista e tecnicista (LANGHI; NARDI, 2011), de modo que a própria prática docente na escola apresenta-se como um reflexo desta formação: um profissional com habilidades reduzidas em relação a um posicionamento reflexivo (SCHÖN, 1983); ou enquanto um intelectual crítico (GIROUX, 1997), não sendo completamente capacitado em usar, responsavelmente, sua autonomia docente (CONTRERAS, 2003), em promover, em seus alunos, o desenvolvimento de senso crítico, segundo a fundamentação deste trabalho. 
DP: O professor apenas perguntava, e quanto mais os alunos respondiam, mais ele os questionava. Os alunos ficaram incomodados e falaram que o professor é "cheio dos porquês".

DP: Os alunos apenas participaram de forma mais ouvinte; quando questionados, afirmavam que não sabiam a resposta, sem muito esforço em arriscar uma explicação.

b) Identificou-se, também, uma resistência com relação ao tipo de avaliação. Demonstraram que não estão habituados a uma dinâmica de reflexão, pois as questões dissertativas das avaliações de Física exigiram um esforço em formular argumentações em sua escrita. Uma habilidade que os PCN (BRASIL, 1999) apontam como essencial e necessária ao desenvolvimento do aluno é expressar-se corretamente utilizando a linguagem física adequada e elementos de sua representação simbólica, apresentando, de forma clara e objetiva, o conhecimento apreendido, por meio de tal linguagem. No entanto, verificou-se que não estão habituados a se manifestar com clareza e sem dificuldades na escrita, mas pareciam aguardar uma avaliação com equações ou perguntas objetivas que priorizam a memorização (questões de múltipla escolha).

DP: Eles se assustaram principalmente por não ser uma prova de alternativas e sim dissertativa [...].

c) Verificou-se que eles não estavam habituados a se manifestar com clareza e sem dificuldades na escrita. Este fato ficou mais claro quando um aluno demonstrou que sabia se expressar oralmente, mas não na escrita.

DP: Um aluno perguntou a respeito da questão, e quando ele perguntava, o professor respondia com outra pergunta. Assim, ele apresentava oralmente seus conceitos com argumentação apoiada no conhecimento cientifico discutido nas aulas. No entanto, não tinha consciência de que as suas justificativas eram as próprias respostas às perguntas da prova e que bastaria colocá-las por escrito.

Visando sintetizar a análise dos dados acima e os resultados obtidos, apresentamos o Quadro 1, que resume os principais aspectos levantados.

\section{Resultados principais: aspectos de conscientização socioambiental sobre a PL}

As categorias acima interpretadas sob uma análise processual e qualitativa levaram-nos à última etapa da Análise Textual Discursiva que, segundo Moraes (2003), indicou a nossa nova compreensão sobre a problemática inicialmente levantada, agora sob a luz dos resultados obtidos e da fundamentação teórica adotada. Trata-se, portanto, da constituição da efetiva contribuição deste estudo, a saber, os aspectos de conscientização socioambiental sobre a PL na perspectiva da abordagem temática, os quais apresentamos a seguir. 
Quadro 1. Síntese dos resultados obtidos

\begin{tabular}{|c|l|}
\hline Categorias & \multicolumn{1}{c|}{ Unitermos } \\
\hline $\begin{array}{c}\text { Consciência } \\
\text { primeira }\end{array}$ & $\begin{array}{l}\text { Falta de segurança; problemas sociais; iluminação exagerada; direitos exigidos; } \\
\text { desconhecimento da PL; cultura de observar o céu noturno; PL é o mesmo que poluição } \\
\text { visual; magnitude; distância das estrelas. }\end{array}$ \\
\hline $\begin{array}{c}\text { Manifestações } \\
\text { sobre a PL }\end{array}$ & $\begin{array}{l}\text { Mau direcionamento das luminárias; iluminação de lugares desnecessários; uso de termo } \\
\text { científico em suas explicações. }\end{array}$ \\
\hline $\begin{array}{c}\text { Tomada de } \\
\text { consciência }\end{array}$ & $\begin{array}{l}\text { Evitar o desperdício de luz; preocupações com a maneira de promover a iluminação; } \\
\text { análise crítica sobre "progresso da sociedade" no que se refere à iluminação; opinião crítica } \\
\text { diante de informações/situações de iluminação; reconhecimento da PL sob o céu noturno. }\end{array}$ \\
\hline $\begin{array}{c}\text { Resistência à } \\
\text { proposta }\end{array}$ & $\begin{array}{l}\text { Resistência à prática do diálogo; postura não reflexiva e não investigadora dos alunos; } \\
\text { dificuldades de expressão escrita; ensino descomprometido com a formação crítica dos } \\
\text { sujeitos. }\end{array}$ \\
\hline
\end{tabular}

Fonte: Elaborado pelos autores.

1. Um ensino dialógico temático, enquanto uma prática cada vez mais consistente na Educação Básica, contribui para a redução da resistência para com tal proposta, pois os alunos deixam de ser condicionados a um processo de ensino mecanicista, em que a informação é apenas transmitida como um produto acabado. Caso contrário, não se consolida uma formação de cidadãos com uma consciência crítica embasada em conceitos científicos, como demonstrado nesta investigação abordando a PL.

2. Futuros trabalhos sobre a construção de uma consciência socioambiental acerca da PL podem levar em conta as concepções alternativas que o futuro cidadão possui (conforme levantados aqui): a iluminação correta é iluminação exagerada, PL é o mesmo que poluição visual, a iluminação excessiva contribui para melhorar a segurança, não precisamos contemplar o céu estrelado, há predominância de preocupações sociais em detrimento das ambientais quando se trata de iluminação pública.

3. Projetos de reformulação de iluminação pública, apresentados aos líderes governamentais, podem obter resultados mais positivos se apelarem para o "aspecto financeiro" e a economia como fatores-chave que justifiquem a mudança, uma vez que não parece haver preocupações, da parte da liderança governamental, com questões energéticas locais, matrizes energéticas nacionais, questões ambientais, céu enquanto patrimônio da humanidade, ou, sequer, com o "direito de ver estrelas" (FLÓRIO, 2009).

4. Opiniões críticas diante de situações-problema reais (como exemplificado neste estudo) podem ser desenvolvidas ao longo de uma sequência didática temática e um trabalho dialógico, segundo os pressupostos freirianos (GEHLEN; MALDANER; DELIZOICOV, 2012), uma vez que os resultados desta pesquisa demonstraram a tomada de consciência acerca da PL na comunidade escolar local.

5. Sob a perspectiva freiriana (DELIZOICOV, 1983), a inserção da Astronomia no ensino deve se constituir uma prática educativa que permita o desenvolvimento de uma postura 
crítica dos educandos diante das contradições sociais onde a escola está inserida, de forma a promover a transformação (como exemplificado pelos resultados desta pesquisa, os alunos construíram uma consciência socioambiental que os potencializou a encontrar soluções, as quais se materializaram, sobretudo, na construção de um protótipo de poste de iluminação; assim, considera-se que estes sujeitos estão em condições de se mobilizarem em prol de uma mudança da realidade local, como, por exemplo, os postes de iluminação da própria escola, ou a elaboração de um manifesto público com argumentos embasados no conhecimento científico trabalhado na escola).

6. Práticas docentes, tais como as desta proposta, constituem um desafio atual, pois, embora os resultados de pesquisa da área e os documentos oficiais nacionais apoiem a abordagem temática no ensino (GEHLEN, 2009), há ainda resistências da parte dos alunos, professores e gestão, uma vez que permanece, insistentemente, a tradição de um ensino "bancário", não apenas na Educação Básica e em alguns referenciais estaduais para o Ensino Médio, mas, também, nos próprios cursos de formação de professores (inicial e continuada), cujas estruturas curriculares revelam um modelo formativo predominantemente conteudista sob a racionalidade técnica, longe de formar um professor intelectual crítico capaz de conduzir seus alunos a uma tomada de consciência fundamentada em conhecimentos científicos (GIROUX, 1997).

\section{Considerações finais}

Ao se analisarem os resultados obtidos por meio desta pesquisa, identificaram-se aspectos que comprovaram a dificuldade do ensino em adequar as novas perspectivas acerca da formação dos sujeitos. Questões relacionadas ao social, ao ambiental, a política e outras não menos importantes são esquecidas ou, mesmo, negligenciadas (até o fato de se conscientizar do direito de simplesmente observar um céu estrelado). Assim, entende-se que ainda há falhas na promoção de uma formação de sujeitos críticos, formação esta, obrigatória legalmente, e que deveria estar contida desde os anos iniciais de estudo.

Essa percepção é algo que preocupa, pois, há a necessidade de garantia de qualidade de vida das gerações futuras, algo que ultrapassa os limites aos quais esta pesquisa se restringiu (Física e Astronomia). Não supervalorizando a educação, ou, mesmo, reduzindo a melhorias necessárias à mesma, os resultados das pesquisas da área apontam que é por meio da formação de sujeitos críticos, atuantes em seu cotidiano, que serão alcançadas melhorias no campo cultural e científico. Entretanto, diante dos resultados aqui obtidos (sobretudo, diante da categoria emergente durante a análise dos dados), percebe-se, também, que existem falhas na formação docente, conforme indicado pelos dados desta investigação, pois os alunos apresentaram certas dificuldades a esta dinâmica, evidenciando uma resistência originária de um processo de condicionamento ocorrido durante os anos escolares anteriores, sob um ensino "bancário" da parte de seus professores, cuja formação profissional talvez tenha sido também assim construída durante suas anteriores trajetórias formativas.

Identifica-se, assim, a necessidade de se constituir um rol de professores intelectuais críticos, segundo um modelo formativo ativista (no sentido de ação transformadora), contribuindo com uma formação inicial que o torne autônomo e consciente de seu papel na educação, promovendo a postura ativista nestes profissionais. Dessa forma, defendemos uma mudança, 
inicialmente, no professor, um dos elementos básicos da escola, de tal forma que este venha a se conscientizar sobre a importância de sua cooperação com as práticas educativas propostas pelos principais resultados de pesquisas da área, visando maior comprometimento com a educação. Mudando o professor, muda-se a escola. No entanto, esforços no caminho inverso, provenientes "de cima para baixo", tentam mudar, primeiramente, a escola e a prática docente, na esperança de que cada professor, automaticamente, se condicione e aceite passivamente tais mudanças. Assim, os resultados obtidos nesta investigação parecem ter conduzido o foco da problemática inicial a uma outra questão importante: a da formação inicial e continuada de professores, que poderá ser tema de futuros estudos nesta linha.

Diante do objetivo sobre o qual este trabalho se norteou, o de investigar elementos de conscientização socioambiental acerca da poluição luminosa, identificamos que esta problemática tornou-se, de fato, presente nos discursos finais dos sujeitos. Diante do reconhecimento desta forma de poluição, a tomada de consciência dos sujeitos, em um nível reflexivo e ativista, consolidou-se no momento da elaboração de um protótipo de poste de iluminação pública. Entretanto, durante a aplicação desta proposta temática, emergiram, nas anotações do diário de pesquisa, indicadores de resistência, por parte dos estudantes, à postura dialógica e questionadora promovida pelo professor durante as discussões. Este comportamento contrário à reflexão e à discussão sinalizou que tais indivíduos estiveram sujeitos a um processo de ensino descomprometido com a formação crítica e política. Nesse sentido, atribui-se ao professor o papel de incentivar tais aspectos, desde os anos iniciais e durante um processo escolar duradouro.

Portanto, consideramos a escolha do tema da poluição luminosa como pertinente ao contexto escolar, tornando-se esta proposta um instrumento para conscientizar indivíduos acerca desta problemática social, apesar de este tipo de poluição ser desconhecida pela população em geral. Adequando-se às premissas da perspectiva freiriana, as discussões ocorridas com o grupo de alunos sobre as questões sociais locais permitiram suas manifestações, tomadas de consciência e incentivo à ação. Dessa forma, esta pesquisa conduziu aos resultados principais: os seis aspectos de conscientização socioambiental sobre a PL, os quais poderão servir de subsídios para futuros estudos nesta área, pois reconhecemos que experiências concretas desta natureza ainda são inexpressivas na pesquisa em ensino de Ciências no Brasil.

\section{Agradecimentos}

Apoio do Programa de fomento do Parque Tecnológico de Itaipu (PTI)/Polo Astronômico Casimiro Montenegro Filho. 
Oliveira, F. A.; Langhi, R.

\section{Referências}

ALBUQUERQUE, V.; LEITE, C. Dialogar sobre a ciência no ensino médio: a importância do (re) olhar constante a esse desafio. In: ENCONTRO DE PESQUISA EM ENSINO DE FÍSICA, 11. 2010. Atas... São Paulo: SBF, 2010. p. 1-12.

ALMEIDA, G. Poluição luminosa: o desperdício inútil dos nossos recursos energéticos. Lisboa, 2009. Disponível em: <http://www.astronomia2009.org/documentos/Poluicao_Luminosa_ GAlmeida.PD>. Acesso em: 20 set. 2011.

BARGHINI, A. Antes que os vaga-lumes desapareçam ou a influência da iluminação artificial sobre o ambiente. São Paulo: Annablume, 2010.

BRASIL. Ministério da Educação e Cultura. Parâmetros curriculares nacionais para o ensino médio. Brasília: Secretaria de Educação Média e Tecnologia, 1999.

. Ministério da Educação e Cultura. Parâmetros curriculares nacionais para o ensino médio: ciências da natureza, matemática e suas tecnologias. Brasília: Secretaria de Educação Média e Tecnológica, 2002.

CARVALHO, A. M. P.; GIL-PÉREZ, D. Formação de professores de ciências: tendências e inovações. 3. ed. São Paulo: Cortez, 1998.

CONTRERAS, J. A autonomia de professores. São Paulo: Cortez, 2002.

DELIZOICOV, D. Ensino de física e a concepção freireana de educação. Revista Brasileira de Ensino de Física, São Paulo, v. 5, n. 2, p. 85-98, 1983.

DELIZOICOV, D.; ANGOTTT, J. P.; PERNAMBUCO, M. M. Ensino de ciências: fundamentos e métodos. São Paulo: Cortez. 2002.

DINIZ, J. C. Combate à poluição luminosa, uma experiência em Nova Friburgo. In:

ENCONTRO NACIONAL DE ASTRONOMIA, 2., 1999, Ouro Preto. Anais... Disponível em: <http://www.astrosurf.com/diniz/combate_a_poluicao_luminosa.html>. Acesso em: 25 set. 2011.

FLICK, U. Introdução à pesquisa qualitativa. Porto Alegre: Artmed, 2009.

FLÓRIO, V. O direito de contemplar o céu. Ciência e Cultura, São Paulo, v. 61, n. 4, p. 52, 2009. Disponível em: <http://cienciaecultura.bvs.br/scielo.php?pid=S0009-67252009000400018\& script=sci_arttext $>$. Acesso em: 20 set. 2011.

FREIRE, P. Pedagogia do oprimido. Rio de janeiro: Paz e Terra, 1984.

FREITAS, A. L. S. Pedagogia da conscientização: um legado de Paulo Freire à formação de professores. 3. ed. Porto Alegre: EDIPUCRS, 2004. 
GAMA, L.; HENRIQUE, A. B. de. Astronomia na sala aula: por quê? Revista Latino-Americana de Educação em Astronomia, São Carlos, n. 9, p. 7-15, 2010. Disponível em: <http://www.relea.ufscar. br/num9/RELEA_A1_n9.pdf>. Acesso em: 06 jun. 2014.

GAMA, L.; ZANETIC, J. Reflexões epistemológicas para o ensino de ciências: questões problematizadoras. In: ENCONTRO NACIONAL DE PESQUISAS EM EDUCAÇÃO EM CIÊNCIAS, 6, 2009, Florianópolis. Atas...Santa Catarina; SBF, 2009. p. 1-13.

GARGAGLIONI, S. R. Análise legal dos impactos provocados pela poluição luminosa do ambiente. 2007. 106 f. Dissertação (Mestrado em Ciências da Engenharia da Energia) - Universidade Federal de Itajubá, Itajubá, 2007.

GEHLEN, S. T. A função do problema no processo ensino-aprendizagem de ciências: contribuições de Freire e Vygotsky. 2009. 253 f. Tese (Doutorado em Educação Científica e Tecnológica) - Universidade Federal de Santa Catarina, Florianópolis, 2009.

GEHLEN, S. T.; MALDANER, O. A.; DELIZOICOV, D. Momentos pedagógicos e as etapas da situação de estudo: complementaridades e contribuições para a educação em ciências. Ciência $\boldsymbol{\&}$ Educação, Bauru, v. 18, n. 1, p. 1-22, 2012.

GIROUX, H. A. Os professores como intelectuais: rumo a uma pedagogia crítica da aprendizagem. Porto Alegre: Artmed, 1997.

KANTOR, C. A. A ciência do céu: uma proposta para o ensino médio. 2001. 116 f. Dissertação (Mestrado em Ensino de Ciências) - Instituto de Física, Universidade de São Paulo, São Paulo, 2001.

LANGHI, R. Astronomia nos anos iniciais do ensino fundamental: repensando a formação de professores. 2009. 370 f. Tese (Doutorado em Educação para a Ciência) - Faculdade de Ciências, Universidade Estadual Paulista, Bauru, 2009.

. Aprendendo a ler o céu: pequeno guia prático para a astronomia observacional. Campo Grande: Ed. UFMS, 2011.

LANGHI, R.; NARDI, R. Interpretando reflexões de futuros professores de física sobre sua prática profissional durante a formação inicial: a busca pela construção da autonomia docente. Investigações em Ensino de Ciências, Porto Alegre, v. 16, n. 3, p. 403-424, 2011.

MARATONA da Via Láctea: um projeto oficial do Ano Internacional da Astronomia 2009, voltado para todos os brasileiros. [S.l.: s.n.], 2009. Disponível em: <http://www.darkskiesawareness.org/files/ Maratona\%20da\%20Via\%20Lactea.pdf>. Acesso em: 12 mar. 2012.

MORAES, R. Uma tempestade de luz: a compreensão possibilitada pela análise textual discursiva. Ciência \& Educação, Bauru, v. 9, n. 2, p. 191-211, 2003.

OLIVEIRA, F. A. Investigando aspectos de conscientização socio-ambiental sobre a poluição luminosa na perspectiva da abordagem temática. 2011. $64 \mathrm{f}$. Trabalho de Conclusão de Curso (Licenciatura em Física) - Universidade Federal de Mato Grosso do Sul, Campo Grande, 2011. Disponível em: <http://sites.google.com/site/proflanghi/tcc201105>. Acesso em: 09 jun. 2014. 
Oliveira, F. A.; Langhi, R.

OLIVEIRA, F. A.; GEHLEN, S. T. O ensino de astronomia por meio da abordagem temática. In: ENCONTRO DE FÍSICA DO CENTRO-OESTE, 1, 2010, Goiânia. Atas... Goiânia: SBF, 2010. Disponível em: <http://www.sbf1.sbfisica.org.br/eventos/extras/iefco/programa/lista_trabalho. asp?sesId=13>. Acesso em: 25 set. 2011.

OLIVEIRA, F. A.; LANGHI, R. Uma proposta de ensino de astronomia por meio da abordagem temática: poluição luminosa como tema. In: SIMPÓSIO NACIONAL DE EDUCAÇÃO EM ASTRONOMIA, 1., 2011, Rio de Janeiro. Anais... Rio de Janeiro: SAB, 2011. p. 1-6.

REZENDE, F; OSTERMANN, F.; FERRAZ, G. Ensino-aprendizagem de física no nível médio: o estado da arte da produção acadêmica no século XXI. Revista Brasileira de Ensino Física, São Paulo, v. 31, n. 1, p. 1401-1408, 2009.

ROS, R. M. Earth-moon-sun system: eclipses models. Proceedings of the International Astronomical Union, Cambridge, n. 233, p. 503-510, 2006.

SANTOS, W. L. P.; MORTIMER, E. F. Uma análise de pressupostos teóricos da abordagem C-T-S (Ciência-Tecnologia-Sociedade) no contexto da educação brasileira. Ensaio: pesquisa em educação em ciências, Belo Horizonte, v. 2, n. 2, p. 133-162, 2002.

SCHÖN, D. A. The reflective practitioner: how professionals think in action. New York: Jossey-Bass, 1983.

VILLANI, A. Reflexões sobre o ensino de física no Brasil: práticas, conteúdos e pressupostos. Revista Brasileira de Ensino de Física, São Paulo, v. 6, n. 2, p. 76-95, 1984.

ZEICHNER, K. A formação reflexiva de professores: idéias e práticas. Lisboa: EDUCA, 1993.

Artigo recebido em 05/07/12. Aceito em 28/08/13 